\title{
Diversion colitis and involution of the defunctioned anorectum
}

\author{
A M Roe, B F Warren, A J M Brodribb, C Brown
}

\begin{abstract}
To measure the effects of defunction in the anorectum, 12 patients (seven men and five women aged 59 (44-81) years) were studied after the Hartmann operation. The operation was for septic complications of diverticular disease in nine and sigmoid carcinoma in three patients. Physiology studies were undertaken 1 and 3 months after surgery, and diversion colitis was assessed endoscopically and by mucosal biopsy at 3 months. There was no change in anal sphincter function by three months. Proctometrogram studies, however, showed an appreciable decrease in rectal volume in all cases, by a mean of $35 \%$ of the 1 month volume. The maximum tolerable volume at 1 month was $157(111-210) \mathrm{ml}$ and at 3 months 87 (71-145) $\mathrm{ml} ; \mathrm{p}<0.01$. There was no change in rectal sensation or compliance. Erythema and granularity without gross erosions or ulceration were found at endoscopy. Histology showed abnormalities in all cases by 3 months. The characteristic features were of a chronic inflammatory cell infiltrate with surface exudate, microscopic erosions, and lymphoid follicular hyperplasia. Crypt abscesses were not a feature at this stage and there was no distortion of crypt architecture. After defunction the previously normal rectum is affected by diversion colitis which, at 3 months, is mild but has characteristics that distinguish the changes from those of inflammatory bowel disease. It is associated with progressive rectal stump involution.

(Gut 1993; 34: 382-385)
\end{abstract}

Diversion colitis is the term given to the inflammatory condition occurring in the defunctioned colon and rectum. It is often not apparent clinically until it becomes symptomatic, with pain and discharge of mucus and blood. ${ }^{12}$ At surgical reanastamosis after the Hartmann operation, the defunctioned rectal stump often seems to have shrunk into the pelvis.

Inspection of the rectal stump in diversion colitis shows mucus plugs, erythema, friability, nodularity, oedema, aphthous ulceration, and erosions with bleeding. ${ }^{2-5}$ The mucosal nodularity and ulceration can be seen on double contrast barium enema ${ }^{6}$ and inflammation can be shown on In-111 labelled white blood cell scan.

Mucosal biopsy specimens show a spectrum of disease comprising acute and chronic inflammation, ' crypt abscesses, ${ }^{13}$ mucin granulomas, and lymphoid follicular hyperplasia with minimal distortion of crypt architecture. ${ }^{89}$ In severe cases the changes may be difficult to distinguish from those of acute ulcerative colitis. ${ }^{911}$ In resected specimens the inflammatory process tends to be confined to the mucosa. ${ }^{8}$ Hypoplasia, with crypt cell production rates decreased by half those of normal, has been described in the defunctioned rectum." Also, impaired bacterial flora in the defunctioned segment has been found, with a reduction in strict anaerobes and an increase in enterobacteria.

The changes of diversion colitis rapidly regress after surgical reanastamosis. ${ }^{13}$ The dependence of colonic epithelial cells on luminal short chain fatty acids is implicated in the aetiology of the condition and successful treatment with topical short chain fatty acids has been reported with regression of the inflammatory changes. 51013

It is not known how rapidly the changes of diversion colitis occur or whether apparent rectal involution after defunction is related to diversion colitis and sequential physiological changes in the defunctioned anorectum have not been previously reported. This study, therefore, aimed to (i) measure changes in physiological parameters of the anorectum with time after defunction and (ii) to describe accurately the histopathological changes that occur in the early defunctioned anorectum.

\section{Patients and methods}

Twelve patients were studied, seven men and five women aged 59 (44-81) years. All had the Hartmann operation, nine for septic complications of diverticular disease and three for sigmoid carcinoma. None of the patients had a diagnosis of inflammatory bowel disease and none had any pre-existing disease of the anorectum.

Physiology studies were undertaken 1 month after operation. This was considered a reasonable time to allow the oversewn rectal stump to heal before pressure volume studies. The studies were repeated at 3 months, before reversal of the operation. Endoscopic and histological assessment of diversion colitis were made at the time of the second physiology studies 3 months after the Hartmann operation.

All patients gave informed consent for the studies, which were approved by the ethical committee of the Plymouth Health Authority.

\section{PHYSIOLOGY}

Standard, $4 \mathrm{~mm}$ water filled microballoon manometry systems were used. These were attached via an external transducer to a Urodynamics System GR860 (Aspen Medical Ltd, Dingwall, Scotland) for screen display and print out recording of the data.

Anal sphincter manometry was used to measure sphincter length, maximum resting pressure, and maximum squeeze pressure.

Proctometrography was used to measure the first sensation of rectal filling, maximum toler- 
able volume and pressure and rectal compliance. A proctometrogram catheter, previously described, was used, ${ }^{1+}$ with water infused at a constant rate of $60 \mathrm{ml} /$ minute. The manometry studies used complied with methods agreed by the working party on anorectal physiology. Reproducibility measurements of the proctometrogram were performed in 14 studies, on the same day, after reintroduction of the catheter.

\section{ENDOSCOPIC INDEX OF DIVERSION COLITIS}

The defunctioned rectum was examined sigmoidoscopically at 3 months and the changes of colitis graded according to the endoscopic index described by Harig et al. ${ }^{5}$ The endoscopic appearances of the rectal stumps were assessed for erythema (score 0-2), oedema (0-1), friability $(0-1)$, granularity $(0-2)$, and erosions $(0-1)$, giving a maximum possible score of 7 .

\section{HISTOLOGY}

Mucosal biopsy specimens were taken at 3 months and graded for changes of colitis using a modified Harig score ${ }^{5}$ by one pathologist unaware of the patients details. The changes of acute and chronic inflammation were graded according to the index described by Warren et al..$^{16}$

\section{Results}

\section{PHYSIOLOGY}

Physiology studies were completed in 10 patients at 1 and 3 months and the results are shown in Table I. Defunction for 3 months had no effect on the anal sphincter with sphincter length and maximum resting and squeeze pressures remaining unchanged.

The most obvious change on proctometrography was the reduction in rectal volume which occurred in all 10 patients by three months; the mean reduction in volume was $35 \%$ of the 1 month volume. This rectal stump shrinkage was not associated with any change in rectal sensation or in rectal compliance.

Two patients had not had the reversal of Hartmann operation performed by 6 months and were therefore available to be studied again. While rectal compliance remained unchanged, rectal volume continued to decrease in both cases.

In 14 proctometrogram studies, the parameters of first sensation, and maximum tolerable volume and pressure were repeated

TABLE I Physiology studies

\begin{tabular}{|c|c|c|c|}
\hline & At 1 month & At 3 months & Significance \\
\hline $\begin{array}{l}\text { Sphincter manometry: } \\
\text { Anal sphincter length } \\
\text { Maximum resting pressure } \\
\text { Maximum squeeze pressure }\end{array}$ & $\begin{array}{l}3 \cdot 0(2 \cdot 5-4 \cdot 0) \\
72(30-103) \\
185(97-423)\end{array}$ & $\begin{array}{l}3 \cdot 0(2 \cdot 5-4 \cdot 0) \mathrm{cm} \\
71(23-130) \mathrm{cm} \mathrm{H}_{2} \mathrm{O} \\
195(96-462) \mathrm{cm} \mathrm{H}_{2} \mathrm{O}\end{array}$ & $\begin{array}{l}\text { NS } \\
\text { NS } \\
\text { NS }\end{array}$ \\
\hline $\begin{array}{l}\text { Proctometrography: } \\
\text { First sensation of rectal filling } \\
\text { Maximum tolerable volume } \\
\text { Maximum tolerable pressure } \\
\text { Rectal compliance }\end{array}$ & $\begin{array}{l}32(25-97) \\
157(111-210) \\
65(40-130) \\
2 \cdot 5(0 \cdot 93-5 \cdot 2)\end{array}$ & 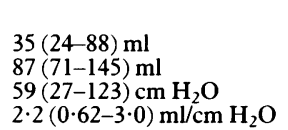 & $\begin{array}{l}\text { NS } \\
\mathrm{p}<0 \cdot 01^{\star} \\
\text { NS }\end{array}$ \\
\hline
\end{tabular}

$\star$ Wilcoxon matched pairs signed ranks test. to assess reproducibility of the technique using the Pearson correlation coefficient. Results were: first sensation coefficient 0.8500 $(\mathrm{p}<0.0001)$, maximum tolerable volume coefficient $0.9886 \quad(\mathrm{p}<0.0001)$, and pressure coefficient $0.9730(\mathrm{p}<0.0001)$. This indicates a highly significant correlation and confirms the reproducibility of the technique even for the sensory measurement where the response is subjective.

\section{ENDOSCOPY}

Endoscopic assessment and histology were assessed in 10 patients, 8 of the patients assessed physiological and two others in whom physiology was not completed. Erythema and granularity were most commonly seen, in nine and eight of the 10 patients respectively. Oedema and friability were seen in five cases each but frank erosions in only one case. In one patient the appearances were normal and, in general, the changes were mild with a median score for the patients of 3 (range 0 to 7 ) out of a maximum of 10 .

\section{HISTOLOGY}

The histological grade ranges from 1 to 14 (median 5, maximum possible score 23 ). The features included erosions, surface exudates, lymphoid follicular hyperplasia, oedema, acute and chronic inflammation, muciphages, pseudolipomatosis, and mucosal prolapse. The most notable features were those of a diffuse chronic inflammatory cell infiltrate (Fig 1) with lymphoid follicular hyperplasia (Fig 2) and erosions overlying the lymphoid follicles, in the absence of crypt distortion with minimal mucin depletion. Abnormalities were found in all 10 patients including the case which appeared normal on inspection. Crypt abscesses were not a feature of the disease at this stage, and there was no change in crypt architecture. At 3 months the changes were generally mild. The two patients who did not undergo reversal by 6 months showed similar histology grading as at 3 months despite progressive rectal shrinkage.

\section{Discussion}

These studies have shown that diversion colitis is present in a mild form in all cases 3 months after defunction and that these changes are associated with rectal involution, with the volume decreasing by $35 \%$. Whether the diversion colitis causes the rectal shrinkage is not clear. In examination of a resected specimen, the changes of diversion colitis were confined to the mucosa, ${ }^{8}$ and another explanation is that the rectal smooth muscle simply undergoes disuse atrophy. However, we have observed in resected specimens from ulcerative colitis patients, that the inflammation in the defunctioned colitic rectum is frequently transmural and this may account for the rectal involution in these cases. ${ }^{17}$

Physiology studies showed no adverse effect on the anal sphincters after defunction for 3 months, and this correlates with the clinical finding that incontinence is rarely a problem 


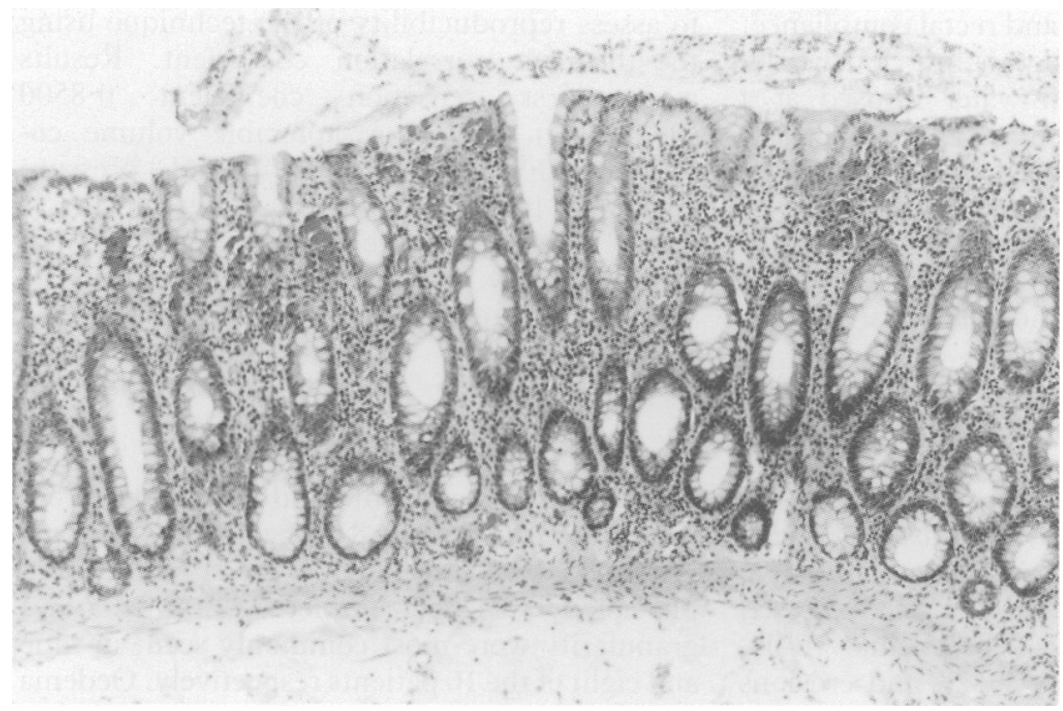

Figure 1: Diversion proctitis with mild chronic diffuse developed metastases distant from the rectal inflammation, surface epithelial degeneration, normal mucin content, and no crypt distortion. (Original magnification $\times 75$ )

Figure 2: Diversion proctitis showing lymphoid follicular hyperplasia with overlying erosion. (Original magnification $\times 75$ )

after reversal of the Hartmann operation. All the patients in this study, apart from one who stump, have had the operation reversed with no major complications. Some diarrhoea is common initially but quickly resolves spontaneously. This may be related to changes in the bacterial flora in the defunctional segment reintroduced into the faecal system. ${ }^{12}$ Despite the increased rectal stump shrinkage with time after defunction, there is no increased morbidity of delaying the reversal of Hartmann operation though it may be technically more problematic with the shrunken rectal stump. ${ }^{18}$ The response to infused short chain fatty acids would seem appropriate in treating symptomatic patients with diversion colitis and may have a role in preventing undue rectal stump involution before reconstructive surgery.

The technique of proctometrography has been criticised on the grounds that the rectum, unlike the bladder in cystometrography, is not a closed organ ${ }^{19}$ and that there is a wide range of values in normal subjects. ${ }^{1+18}$ However, the technique seems ideally suited to this type of study where the rectal stump is closed and longitudinal studies are made in the same patient. We have

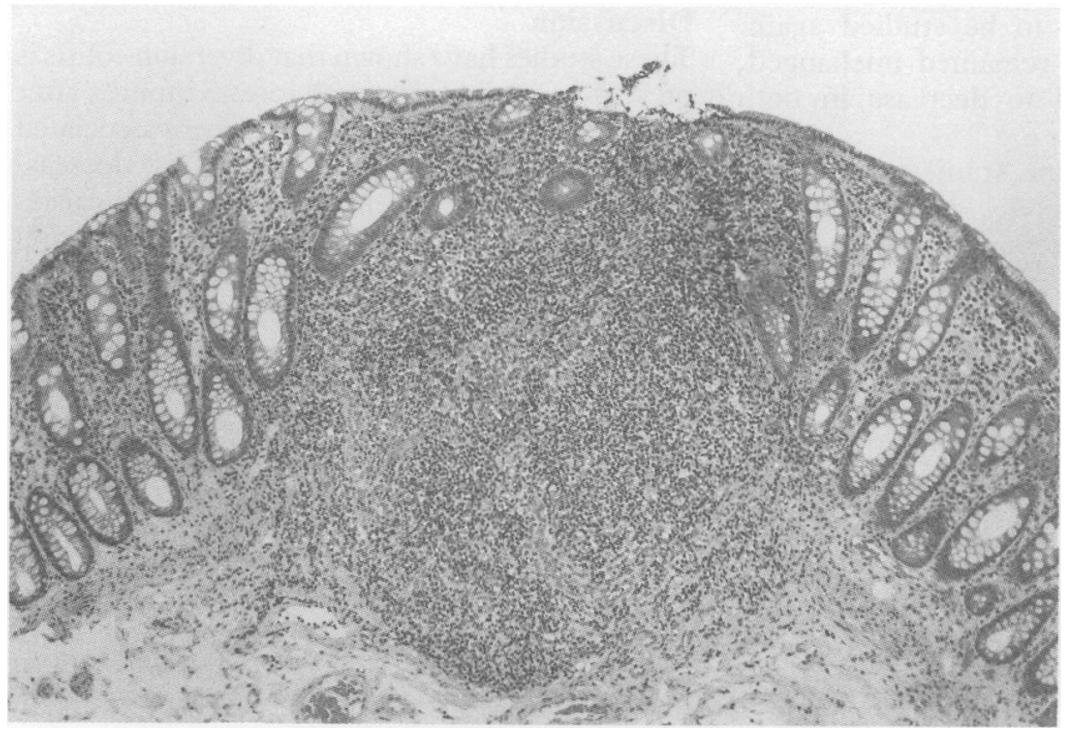

found the technique highly reproducible, and this has been previously confirmed by Varma et al. ${ }^{20}$ The sensory test of threshold sensation is also surprisingly reproducible for a subjective test and this finding has been previously reported with other sensory tests of anorectal function. ${ }^{21} .2$

Although the histological features of diversion colitis show some degree of overlap with inflammatory bowel disease, ${ }^{23}$ some features are characteristic. The most striking single feature of diversion colitis, even at the early stage described in this paper, is the presence of lymphoid hyperplasia, sometimes with overlying superficial erosions. This change is always apparent whether in the defunctioned normal rectum as here, the proctitic rectum, ${ }^{17}$ or the rectum in children with Hirschprung's disease, ${ }^{23}{ }^{2+}$ and has also been observed in the defunctioned pelvic ileal reservoir. ${ }^{25}$ Occasionally the superficial erosions resemble ischaemia or pseudomembranous colitis, ${ }^{17}$ but the other features of diversion colitis are present. Other features are a notable lack of crypt distortion and mucus depletion in the presence of varying degrees of chronic and acute inflammation, which tends to be diffuse.

The study has shown that diversion colitis occurs at an early stage after defunction in the normal rectum. Consistent and characteristic histological features can be shown and the inflammatory changes are associated with a progressive reduction in the volume of the defunctioned rectum.

We would like to thank the Departments of Medical Physics and Urodynamics in Plymouth for their valuable help with the physiology studies.

This paper was presented in a poster form at the British Society of Gastroenterology meeting in Southampton, Autumn 1990.

1 Glotzer DJ, Glick ME, Goldman H. Proctitis and colitis following diversion of the fecal stream. Gastroenterology 1981; 80: 438-41.

2 Haas PA, Fox TA. The fate of the forgotten rectal pouch after Hartmann's procedure without reconstruction. Am F Surg 1990; 159: 106-10.

3 Korelitz BI, Cheskin LJ Sohn N, Sommers SC. The fate of the rectal segment after diversion of the faecal stream in Crohn's disease: its implications for surgical management. 7 Clin Gastroenterol 1985; 7: 37-43.

4 Lusk LB, Reichen J, Levine JS. Aphthous ulceration in diversion colitis. Clinical implications. Gastroenterolog 1984; 87: 1171-3.

Harig JM, Soergel KH, Komorowski RA, Wood CM. Treatment of diversion colitis with short-chain fatty acid irrigation. New Engl f Med 1989; 320: 23-8.

6 Scott RL, Pinstein ML. Diversion colitis demonstrated by double contrast barium enema. Am $\mathcal{f}$ Radiol 1984; 143: 767-8.

7 Stein DT, Paldi JH, Goodwin DA. In-III leukocyte scan in 'diversion' colitis. Clin Nucl Med 1983; 8: 1-2.

8 Murray FE, O'Brien MJ, Birkett DH, Kennedy SM, Lamont JT. Diversion colitis. Pathological findings in a resected
sigmoid colon and rectum. Gastroenterology 1987; 93: sigmoid

9 Ma CK, Gottlieb C, Haas PA Diversion colitis: A clinicopathologic study of 21 cases. Hum Pathol 1990; 21 : 429-36.

10 Komorowski RA. Histological spectrum of diversion colitis. Am 7 Surg Pathol 1990; 14: 548-54.

11 Appleton GVN, Williamson RCN. Hypoplasia of defunctioned rectum. Br F Surg 1989; 76: 787-89.

12 Neut C, Colombel JF, Guillemot F, et al. Impaired bacteria flora in human excluded colon. Gut 1989; 30:1094-8.

13 Agarwal VP, Schimmel EM. Diversion colitis: a nutritional deficiency syndrome? Nutr Rev 1989; 47: 257-61.

14 Roe AM, Bartolo DCC, Mortensen NJ McC. The diagnosis and surgical management of intractable constipation. Br 7 Surg 1986; 73: $85+61$

15 Keighley MRB, Henry MM, Bartolo DCC, Mortensen NJ McC. Anorectal physiology mesurement: report of a work ing . Antectal physiology mesurem

16 Warren BF. Rigby HS, Neumann C . al. The role of multiple biopsies in longstanding ulcerative colitis. 7 Pathol 1988 ; 155: $347 \mathrm{~A}$.

17 Warren BF, Shepherd NA, Bartolo DCC, Bradfield JWB The defunctioned rectum in ulcerative colitis. Gut (in press). 
18 Roe AM, Ali A, Pradhu S, Brown C, Brodribb AJM. Reversa of Hartmann's procedure: timing and operative technique. Br7 Surg 1991; 78: 1167-70.

19 Madoff RD, Orrom WJ, Rothenberger DA, Goldberg SM Rectal compliance: a critical reappraisal. Int $\mathcal{F}$ Colorectal Disease $1990 ; 5: 37-40$

20 Varma JS, Smith AN. Reproducibility of the proctometrogram. Gut 1986; 27: 288-92.

21 Roe AM, Bartolo DCC, Mortensen N J McC. New method of assessment of anal sensation in various anorectal disorders. BrF Surg 1986; 25: 1279-82.

22 Rogers J, Laurberg S, Misiewicz JJ, et al. Anorecta physiology validated: a repeatability study of the motor and sensory tests of anorectal function. Br 7 Surg 1989; 76 : 607-9 tests of anorectal function. Br f Surg 1989; 76:

23 Geraghty JM, Talbot IC. Diversion colitis: histological features in the colon and rectum after defunctioning colostomy. Gut 1991; 32: 1020-23.

24 Warren BF, Vujanie GM, Noblett HR, Berry PJ. The defunctioned rectum in Hirschprung's disease. F Pathol 1992; 168: 145.

25 Drut R, Drut RM. Lymphoglandular hyperplasia in segments of the colon for defunctionalised Hirschprung's disease. Ped Pathol 1991; 11: 340. 